\title{
Rinite micótica rinofaríngea em um ovino Texel no Rio Grande do Sul
}

\author{
Rhinopharyngeal mycotic rhinitis in a Texel sheep in Rio Grande do Sul \\ Pedro Miguel Ocampos Pedroso, Djeison Lutier Raymundo, Pedro Soares Bezerra Júnior, Eduardo \\ Conceição de Oliveira, Luciana Sonne, André Gustavo Cabrera Dalto \& David Driemeier
}

\begin{abstract}
RESUMO
Rinite micótica é uma doença granulomatosa de ocorrência pouco frequente que acomete o homem e os animais. Recentemente, no Centro-Oeste e Nordeste do Brasil foram descritos casos de rinite micótica em ovinos. Em uma propriedade no município de Parobé, Rio Grande do Sul, Sul do Brasil adoeceram e morreram, desde janeiro de 2007, 4 ovinos de um total de 30 animais. Os animais apresentavam dificuldade respiratória, intolerância ao exercício e secreção serossanguinolenta pelas narinas e morte após alguns dias. Um quinto animal doente foi encaminhado ao Setor de Patologia Veterinária da UFRGS para exame clínico e necropsia. O ovino apresentava dificuldade respiratória devido à obstrução parcial dos orifícios nasais, intolerância ao exercício, espirros e corrimento nasal serossanguinolento bilateral. Os principais achados de necropsia foram massas de coloração amarelada irregular, friável e com coágulos de sangue na região etmoidal, conchas nasais e coanas do lado esquerdo. Foram encontrados ainda, pequenos nódulos no lóbulo pulmonar diafragmático esquerdo. Na microscopia da mucosa da cavidade nasal apresentava necrose multifocal, contendo estruturas semelhantes a hifas e circundadas por infiltrado de neutrófilo, macrófagos e células gigantes. Cérebro com focos necróticos piogranulomatosos na leptomeninge das porções frontais. Na coloração de Gomori metenamina-prata, foram observadas hifas, irregulares e raramente septadas e na imunohistoquímica para Pythium insidiosum, obteve-se resultado negativo. A morfologia das hifas fúngicas no tecido é característica de Conidiobolomicose.
\end{abstract}

Descritores: rinite micótica, ovino, Rio Grande do Sul, Sul do Brasil.

\section{ABSTRACT}

Mycotic rhinitis is a granulomatous disease of infrequent occurrence that affects man and animals. Recently in the Center-West and Northeast of Brazil cases of mycotic rhinitis have been described in sheep. A farm in the city of Parobé, Rio Grande do Sul, Southern Brazil four sheep died of a total thirty animals since january of 2007. The animals showing respiratory distress, intolerance to exercise and exudate on the nasal orifices and death after some days. One fifth seek sheep was sent to the Sector of Veterinary Pathology of the UFRGS for clinical examination and necropsy. The ovine presented respiratory distress due to partial blockage of the nasal orifices, intolerance to exercise, sneeze and bilateral serosanguineous nasal discharge. The main necropsy findings of the animal was friable yellowish and irregular masses in the ethmoidal region, nasals mucosa and choanal shells. In the left diaphragmatic pulmonary lobe two yellowished small $0,5 \mathrm{~cm}$ of diameter nodules were found. Histological examination of nasal mucosa and pulmonary nodules revealed multifocal necrosis with neutrophils macrophages and giant cells infiltrate surrounded hyphal structures. The brain presented piogranulomatous necrotic focus in the leptomeninge of the frontal lobule. Gomori methenamine-silver staining showed many hyphae. They were irregular and rarely septate. The immunohistochemistry for Pythium insidiosum was negative. Morphological aspects of the fungi structures in tissue are typical with Conidiobolomycosis.

Keywords: mycotic rhinitis, ovine, Rio Grande do Sul, Southern Brazil. 


\section{INTRODUÇÃO}

Zigomicoses são micoses subcutâneas causadas por fungos do solo, que geralmente manifestamse como uma infiltração granulomatosa crônica da submucosa nasal, estendendo-se para o tecido subcutâneo e pele da face [19]. A zigomicose é causada por espécies dos gêneros Basidiobolus e Conidiobolus (Entomoftoromicose) e tem sido registrada em várias partes do mundo com relatos em ovelhas $[2,6,8,15]$, cavalos [5,20], mula [3], lhamas [7], veado [18] e pessoas [19]. Duas formas clínicas da enfermidade têm sido diagnosticadas: uma rinofaríngea que afeta a região etmoidal, conchas nasais, seios paranasais, palato mole, órbita, faringe, músculos e linfonodos $[1,13,16]$ e a forma rinofacial, que afeta o vestíbulo nasal, união mucocutânea do nariz, lábio superior, pele do focinho e palato duro $[1,16]$. Microscopicamente, ambas as lesões consistem em granulomas multifocais, com uma área central necrótica, contendo hifas com paredes finas, raramente septadas e com ramificações laterais, sendo rodeadas por material de Splendore-Hoeppli [13]. Surtos de ambas as formas de rinite micótica já foram descritas em ovinos no Nordeste e Centro-Oeste brasileiro [1,14,16,17].

O objetivo deste trabalho é relatar um caso de rinite micótica rinofaríngea em um ovino da raça Texel no Estado do Rio Grande do Sul.

\section{RELATO DE CASO}

Foi encaminhado ao Setor de Patologia Veterinária (SPV) da Universidade Federal do Rio Grande do Sul (UFRGS), no período de abril de 2007, um ovino fêmea, da raça Texel, com três anos de idade,

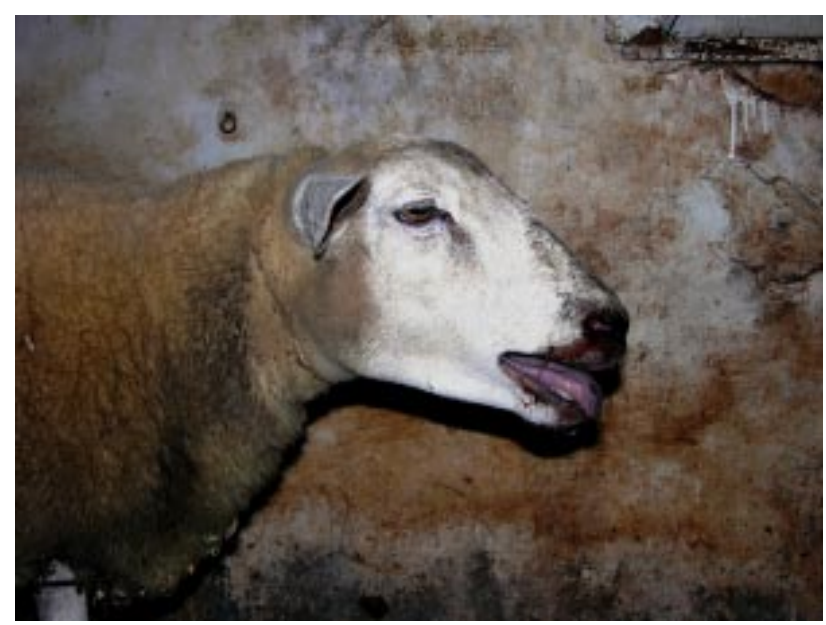

Figura 1. Ovino apresentando dificuldade respiratória quando movimentado. proveniente do município de Parobé, RS. Foi realizado exame clínico e, em decorrência do estado debilitado do animal, esse foi submetido à eutanásia. Os dados epidemiológicos e histórico foram obtidos com o médico veterinário que atendeu a propriedade e o quadro clínico observado pela equipe do SPV-UFRGS. Durante a realização da necropsia, fragmentos de órgãos foram fixados em formalina tamponada a $10 \%$, incluídos em parafina, cortados a 5 micras de espessura e corados pela técnica de hematoxilina e eosina (HE) e coloração de Gomori metenamina-prata (GMS) [11]. Não foi enviado material para cultura e identificação do agente. Adicionalmente, fragmentos de tecido da cavidade nasal foram submetidos à técnica de imuno-histoquímica para pitiose [9] utilizando-se anticorpo primário policlonal anti-Pythium insidiosum [10] na diluição de $1: 100$ por uma hora a $37^{\circ} \mathrm{C}$. A revelação dos cortes foi realizada com o cromógeno vermelho ${ }^{1}$ por 5 minutos em temperatura ambiente. Foram inseridos controles positivos de $P$. insidiosum e como controle negativo foi incluído um caso de infecção por Conidiobolus spp. [1]. Os controles foram confirmados com isolamento e identificação do agente na lesão.

Segundo o médico veterinário que atendeu a propriedade, desde janeiro de 2007, haviam adoecido e morrido 4 ovinos de um total de 30 animais. Estes animais apresentaram um quadro clínico de dificuldade respiratória, intolerância ao exercício, com secreção serossanguinolenta unilateral ou bilateral pelas narinas e morte após alguns dias. A propriedade apresentava muitas áreas úmidas e que alagavam quando havia períodos de chuvas. No exame clínico,

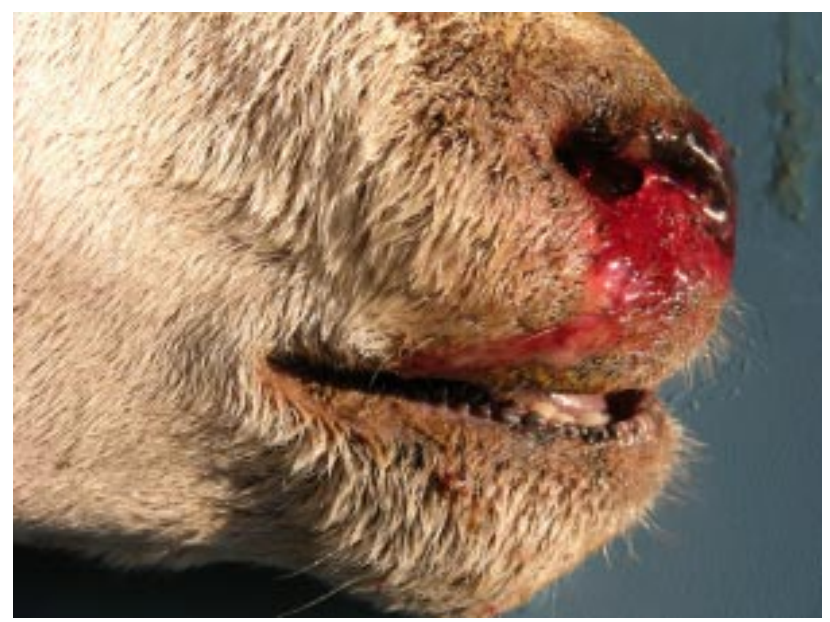

Figura 2. Corrimento serossanguinolento pelas narinas. 


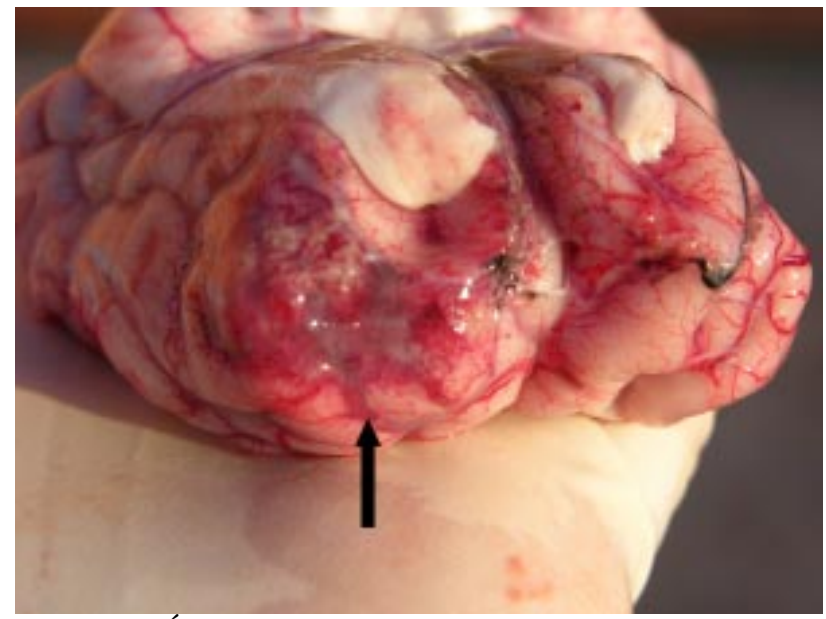

Figura 3. Área de coloração avermelhada (seta) na região frontal do encéfalo.

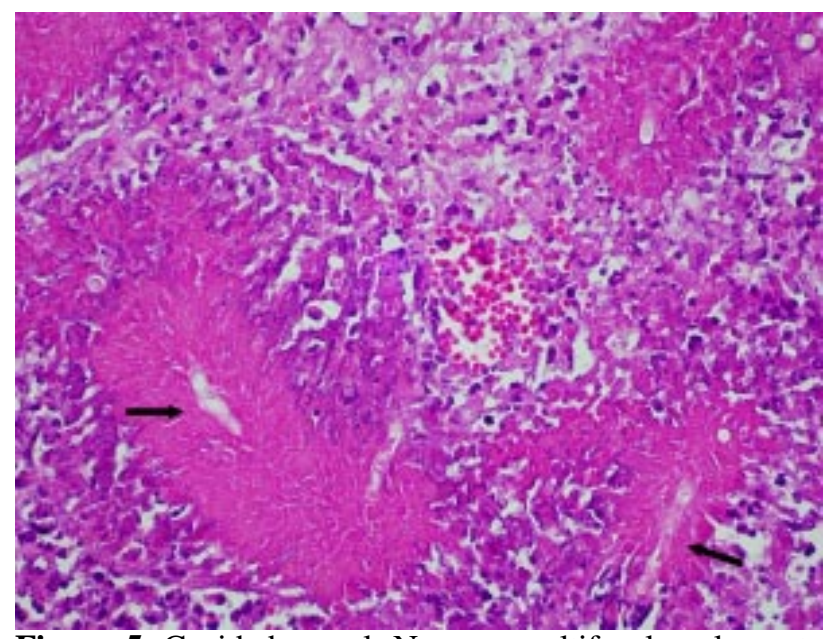

Figura 5. Cavidade nasal. Necrose multifocal coalescente contendo estruturas semelhantes a hifas fracamente coradas (setas) rodeadas por material do tipo Splendore-Hoeppli (HE, Obj 40).

o ovino apresentava dificuldade respiratória (Figura 1) devido à obstrução parcial dos orifícios nasais, quando movimentado, apresentava intolerância ao exercício, espirros e corrimento nasal serossanguinolento bilateral (Figura 2). Durante a necropsia, foi retirado o encéfalo e notou-se infiltração pela placa cribiforme, atingindo a meninge e a região frontal do encéfalo, evidenciando-se áreas de coloração avermelhadas (Figura 3). Logo após, a cabeça foi seccionada longitudinalmente sobre a linha mediana dorsal e observou-se massas de coloração amarelada irregular, friável e com coágulos de sangue na região etmoidal, conchas nasais e coanas (Figura 4). Nos pulmões, havia dois nódulos de aproximadamente $0,5 \times 0,5 \mathrm{~cm}$ de diâmetro, de coloração amarelada e translúcido no lóbulo pulmonar diafragmático esquerdo. $\mathrm{Na}$ microscopia da mucosa da cavidade nasal, havia

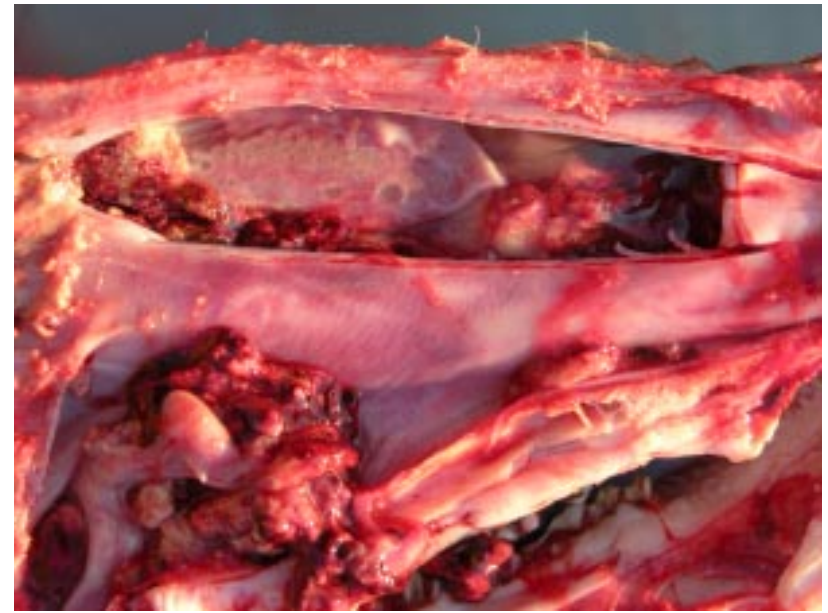

Figura 4. Corte longitudinal da cabeça. Presença de massas de coloração amarelada irregular, friável e com coágulos de sangue na região etmoidal, conchas nasais e coanas.

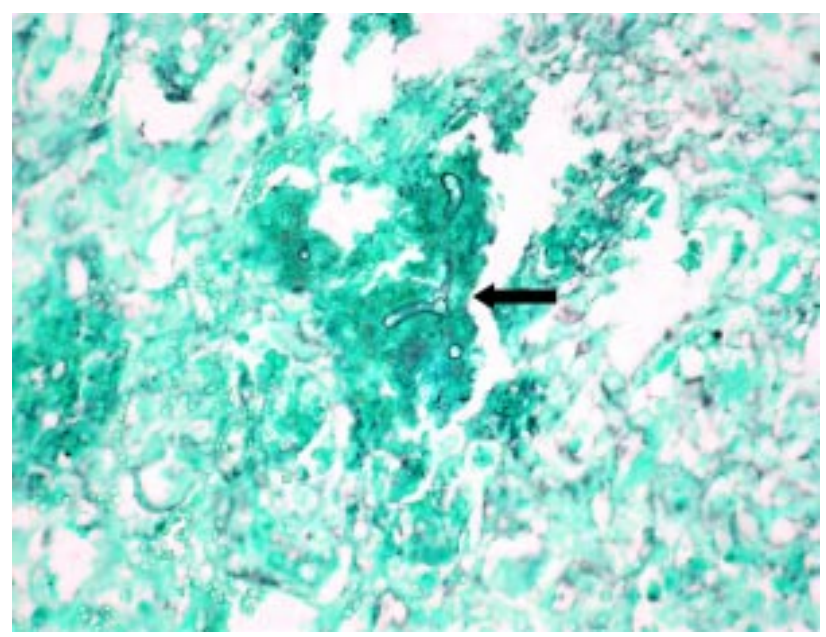

Figura 6. Hifas irregulares, dilatação balonosa na extremidade e raramente septadas (seta). Coloração de Gomori metenamina-prata (GMS, Obj 20).

necrose multifocal coalescente, contendo estruturas semelhantes a hifas fracamente coradas e circundadas por infiltrado de neutrófilos, macrófagos e células gigantes tipo multinucleada, além de tecido conjuntivo fibroso arranjados de forma paralela ao redor da área de necrose (Figura 5). No pulmão, foram observadas áreas de necrose circundadas por infiltrado fibrinossupurativo focal, contendo estruturas semelhantes a hifas fracamente coradas e rodeadas por material de Splendore-Hoeppli. No cérebro havia focos necróticos piogranulomatosos na leptomeninge, com manguitos perivasculares no córtex cerebral subjacente, estendendo-se até a substância branca. Na coloração de GMS ,foram observadas numerosas hifas, irregulares, com dilatação balonosa na extremidade e raramente septadas (Figura 6), sugerindo-se tratar de conidiobolomicose. Dos fragmentos submetidos à 
técnica de imuno-histoquímica não houve marcação, identificando-se somente imagens negativas de estruturas fúngicas em forma de hifa. Os controles para $P$. insidiosum e Conidiobolus spp. utilizados tiveram resultados positivo e negativo respectivamente.

\section{DISCUSSÃO}

A identificação presuntiva do agente fúngico envolvido foi realizado pela observação histopatológica, características morfológicas das hifas, do local da lesão e diagnóstico negativo para pitiose pela técnica de imuno-histoquímica sugerem que tenha sido causada por fungo do gênero Conidiobolus.

O quadro clínico caracterizado por dificuldade respiratória e descarga nasal serossanguinolenta ou mucossanguinolenta são sinais clínicos característi$\cos$ da forma rinofaríngea da conidiobolomicose descrita em ovinos $[1,6,8,17]$. O ovino deste estudo apresentava massa de coloração amarelada e friável com localização na região etmoidal, conchas nasais e coanas, característica da forma rinofaríngea da conidiobolomicose e semelhante à descrita por outros autores no Brasil $[1,17]$. Outras lesões macroscópicas observadas no ovino como nódulos no pulmão, infiltração pela placa cribiforme, atingindo a meninge, o encéfalo e o bulbo olfatório também foram observados em casos nos estados de Mato Grosso e no Nordeste do Brasil $[1,16,17]$, podendo também serem encontradas em linfonodos, abomaso, rins e coração [1,16,17]. A principal lesão microscópica no ovino foi de estruturas semelhantes a hifas fracamente coradas e raramente septadas, circundadas por infiltrado de neutrófilos, macrófagos e células gigantes, sendo melhor visualizada na impregnação pela prata
(GMS), na qual evidenciam-se hifas largas, com parede fina, escassos septos e dilatação balonosa na extremidade, característico do gênero Conidiobolus [1].

É importante realizar o diagnóstico diferencial de Tumor etmoidal enzoótico que apresenta um curso clínico mais prolongado e diferente lesões macroscópicas e microscópicas [4]. Basidiobolus spp. tem características morfológicas semelhantes ao Pythium insidiosum, mas afeta preferencialmente o tecido subcutâneo [15]. Pythium insidiosum que causa doença com achados clínico-patológicos semelhantes, provoca uma reação de Splendore-Hoeppli mais discreta e as hifas são mais finas e com paredes mais espessas [14]. Um fato importante deste relato é que se obteve resultado negativo para Pythium insidiosum pela técnica de imuno-histoquímica. A probabilidade de falso positivo na imuno-histoquímica é pequena, uma vez que as hifas de $P$. insidiosum apresentam moléculas antigênicas com epítopos específicos do Reino Chromista, que não são encontrados nas hifas dos fungos zigomicetos [12].

Este relato é a primeira descrição de rinite micótica na forma rinofaríngea compatível com Conidiobolus spp. em ovino Texel no Estado do Rio Grande do Sul. Nos outros casos, descritos nas regiões Nordeste e Centro-Oeste, a enfermidade acometeu ovinos deslanados predominantemente puros e mestiços das raças Santa Inês e Morada Nova $[1,16,17]$.

Agradecimentos. Ao Prof. Dr. Edson Moleta Colodel da Universidade Federal de Mato Grosso (UFMT), pelos controles positivos e negativos utilizados neste trabalho. Ao Conselho Nacional de Desenvolvimento Científico e Tecnológico (CNPq) pelo apoio financeiro.

\section{REFERÊNCIAS}

1 Boabaid F.M., Ferreira E.V., Arruda L.P., Gasparetto N.D., Souza R.L., Silva M.C., Dutra V., Nakazato L. \& Colodel E.M. 2008. Conidiobolomicose em ovinos no Estado de Mato Grosso. Pesquisa Veterinária Brasileira. 28: 77-81.

2 Carrigan M.J., Small A.C. \& Perry G.H. 1992. Ovine nasal zygomycosis caused by Conidiobolus incongruus. Australian Veterinary Journal. 69: 237-240.

3 Carvalho E.C.Q., Cruz J.B. \& Nascimento R.L. 1976. Rinoficomicose em muar. Pesquisa Agropecuária Brasileira. 11: 1317.

4 Fernandes C.G. 2007. Tumor enzoótico nasal. In: Riet-Correa F., Schild A.L., Lemos R.A.A. \& Borges J.R.J. (Eds). Doenças de Ruminantes e Equídeos. 3. ed. Santa Maria: Pallotti, p. 654.

5 Humber R.A., Brown C.C. \& Kornegay R.W. 1989. Equine zygomycosis caused by Conidiobolus lamprauges. Journal of Clinical Microbiology. 27: 573-576.

6 Ketterer P.J., Kelly M.A., Connole M.D. \& Ajello L. 1992. Rhinocerebral and zygomycosis in sheep caused by Conidiobolus incongruus. Australian Veterinary Journal. 69: 85-87. 
7 Moll H.D., Schumacher J. \& Hoover T.R. 1992. Entomophthoramycosis conidiobolae in a llama. Journal of the American Veterinary Medical Association. 200: 969-970.

8 Morris M., Ngeleka M., Adogwa A.O., Lalla G., St-Germain G. \& Higgins R. 2001. Rhinocerebral zygomycosis in a sheep. The Canadian Veterinary Journal. 42: 227-228.

9 Pedroso P.M.O., Bezerra Júnior P.S., Dalto A.G.C., Cavalheiro A.S., Santurio J.M. \& Driemeier D. 2007. Diagnóstico histopatológico e imunoistoquímico de pitiose cutânea em eqüinos. In: Anais da VII Conferência Sul-Americana de Medicina Veterinária. (Rio de Janeiro, Brasil). pp.107-109.

10 Pereira D.I.B. 2008. Suscetibilidade in vitro e in vivo de Pythium insidiosum: estudo comparativo entre acetato de caspofungina e imunoterapia em coelhos. 117f. Porto Alegre, RS. Tese (Doutorado em Ciências Veterinárias)-Programa de Pós-graduação em Ciências Veterinárias, Universidade Federal do Rio Grande do Sul.

11 Prophet E.B., Mills B., Arrington J.B. \& Sobin L.H. 1992. Laboratory Methods in Histotechnology. Washington: American Registry of Pathology, 279p.

12 Reis Júnior J.L. \& Nogueira R.H.G. 2002. Estudo anatomopatológico e imunoistoquímico da pitiose em equinos naturalmente infectados. Arquivo Brasileiro de Medicina Veterinária e Zootecnia. 54: 358-365.

13 Riet-Correa F. 2007. Conidiobolomicose em ovinos. In: Riet-Correa F., Schild A.L., Lemos R.A.A. \& Borges J.R.J. (Eds). Doenças de Ruminantes e Eqüídeos. 3.ed. Santa Maria: Pallotti, p. 448-450.

14 Riet-Correa F., Dantas A.F.M., Azevedo E.O., Simões S.D.V., Silva S.M.S., Vilela R. \& Mendoza L. 2008. Outbreaks of rhinofacial and rhinopharingeal zygomycosis in sheep in Paraíba, northeastern Brazil. Pesquisa Veterinária Brasileira. 28: 29-35.

15 Riet-Correa F., Tabosa I.M., Azevedo E.O., Medeiros R.M., Simões S.V.D., Dantas A.F., Alves C.J., Nobre V.M.T., Athayde A.C., Gomes A.A. \& Lima E.F. 2003. Doenças de ruminantes e eqüinos no semi-árido da Paraíba. Semi-Árido em Foco. 1: $2-86$.

16 Silva S.M.M.S, Castro R.S., Costa F.A.L., Vasconcelos A.C., Batista M.C.S., Riet-Correa F. \& Carvalho E.M.S. 2007. Conidiobolomycosis in sheep in Brazil. Veterinary Pathology. 44: 314-319.

17 Silva S.M.M.S, Castro R.S., Costa F.A.L., Vasconcelos A.C., Batista M.C.S., Riet-Correa F., Carvalho E.M.S. \& Lopes J.B. 2007. Epidemiologia e sinais clínicos da conidiobolomicose em ovinos no Estado do Piauí. Pesquisa Veterinária Brasileira. 27: 184-190.

18 Stephens C.P. \& Gibson J.A. 1997. Disseminated zygomycosis caused by Conidiobolus incongruu in a deer. Australian Veterinary Journal. 75: 358-359.

19 Tadano T., Paim N.P., Hueb M. \& Fontes C.J.F. 2005. Entomoftoromicose (zigomicose) causada por Conidiobolus coronatus em Mato Grosso (Brasil): relato de caso. Revista da Sociedade Brasileira de Medicina Tropical. 38: 188-190.

20 Zamos D.T., Schumacher J. \& Loy J.K. 1996. Nasopharyngeal conidiobolomycosis in a horse. Journal of the American Veterinary Medical Association. 208: 100-101. 